\title{
ANÁLISES E REFLEXÕES SOBRE A FORMAÇÃO DOCENTE E O ENSINO DE FÍSICA EXPERIMENTAL NO RIO GRANDE DO NORTE
}

\author{
J. C. S. Borges' e I. R. Rocha ${ }^{2}$ \\ ${ }^{1}$ Licenciatura em Física - Instituto Federal do Rio Grande do Norte e ${ }^{2}$ Universidade Gama Filho \\ cousteau.borges@ifrn.edu.br-prof.ingridribeiro@posead.com.br
}

Artigo submetido em março/2012 e aceito em junho/2012

\section{RESUMO}

O presente trabalho traz uma discussão sobre o ensino experimental da disciplina de Física no estado do Rio Grande do Norte. A Física é, em sua essência, uma ciência experimental, embora a realidade das salas de aula brasileiras tende a demonstrar o contrario, pautando a disciplina em conceitos estanques e um formalismo matemático excessivo. Felizmente, têm-se observado uma mudança desse cenário em âmbito nacional, e verificou-se nesse trabalho se o Rio Grande do Norte acompanha essa tendência. Para isso, foram elaborados dois momentos de análise distintos. No primeiro, Verificou-se a existência da prática experimental nas escolas de ensino médio. Para esse quesito, analisaram-se as escolas com os melhores indicadores IDEB. Por fim, um questionário foi elaborado e levado aos alunos de cursos de Licenciatura em Física, em diferentes cidades do Estado. Nesse momento, a aplicação do questionário distinguiu alunos da licenciatura em Física em ingressantes, concluintes e alunos cursando alguma disciplina de Física Experimental. Por fim, os resultados foram analisados e discutidos, mostrando uma evolução do ensino no Rio Grande do Norte, e uma prática experimental crescente e motivadora.

PALAVRAS-CHAVE: Física experimental, IDEB, formação docente.

\section{ANALYSIS AND REFLECTIONS ON TEACHING AND LEARNING OF EXPERIMENTAL PHYSICS IN RIO GRANDE DO NORTE}

\begin{abstract}
This paper presents a discussion of the experimental teaching of the discipline of physics in the state of Rio Grande do Norte. Physics is, in essence, an experimental science, but the reality of classrooms in Brazil tend to demonstrate the contrary, scheduling discipline on concepts and mathematical formulas too tight. Fortunately, it has been observed a change in this scenario at the national level, and found work in the Rio Grande do Norte follow this tendency. Thus, we prepared two times. At first, verified the existence of experimental practice in high schools (public and
\end{abstract}

private). To this question, we analyzed the top 10 schools in Rio Grande do Norte, according to data from IDEB. Finally, a questionnaire was prepared and taken to the students of undergraduate courses in physics, in different cities of the state. In this third phase, the questionnaire distinguished graduate students in physics entrants, graduates and students enrolled in a course of Experimental Physics. Finally, the results were analyzed and discussed, showing an evolution of education in Rio Grande do Norte, and a growing experimental practice and motivating.

KEY-WORDS: Experimental physics, IDEB, teacher training. 


\section{ANÁLISES E REFLEXÕES SOBRE A FORMAÇÃO DOCENTE E O ENSINO DE FÍSICA EXPERIMENTAL NO RIO GRANDE DO NORTE}

\section{INTRODUÇÃO}

Um professor de Física, no primeiro dia de aula, faz a seguinte pergunta a seus alunos, que até então, não tiveram a oportunidade de estudar essa disciplina:

\section{Em relação às palavras "ciência", ou "cientista", o que vêm a sua cabeça?}

Alves (2000) coloca que as imagens mais comuns a essa pergunta são o gênio louco que inventa coisas fantásticas, ou o individuo que pensa o tempo todo em fórmulas e cálculos. $E$ às vezes ambos! O que acontece é que os meios de comunicação acabam gerando esses personagens que quase sempre aparecem descabelados, trajando um jaleco não tão limpo e cheios de idéias malucas e bugigangas.

Até que ponto esses personagens fictícios se aproximam do cientista real? O que os alunos começariam a pensar se o professor afirmar que estudar Física é estudar uma parte da ciência e que os Físicos também são cientista? Provavelmente eles teriam a impressão que as aulas dessa tal "Física" seriam semelhante às experiências de laboratório e aos cálculos incompreensíveis de sua imaginação. Infelizmente, o professor da atualidade tende a se tornar apenas o calculista, fazendo com que a Física se distancie da prática experimental.

O ensino atual de Física no Brasil tem se restringindo, em sua maioria, a resolução de exercícios em preparação ao vestibular. Tal situação é comprovada ao observarmos o uso indiscriminado de livros e apostilas recheados de exercícios preparatórios para as provas de vestibular e que, na sua essência, primam pela memorização e pelas soluções algébricas (ROSA, 2005)

A maioria dos livros que circulam nas escolas apresenta os conteúdos como conceitos estanques, dando o caráter de Ciência acabada e imutável à Física. Na perspectiva de Souza (2002), os autores dos livros estariam dando essa ênfase demasiada nos vestibulares, como forma de mostrar a sua preocupação com o futuro do aluno.

Quando se discute ensino médio (que é a ultima etapa da educação básica), rapidamente se pensa em vestibular, emprego ou outra forma de ascensão para o estudante que pretende concluí-lo. Infelizmente, "Costuma-se justificar certa inércia para algumas mudanças no ensino médio (ou mesmo no fundamental) no fato deste ser, presume-se, voltado para o vestibular" (LIMA, 2003, p.6).

Dentro dessa política educacional de "o que o vestibular cobrar na prova, será ensinado na sala", levam vantagem às escolas privadas: "[...] a rede privada prepara o aluno somente para um exame-padrão, o Vestibular." (NEVES, 2000, p.7).

Dessa forma, os alunos se deparam apenas com leis já formuladas, prontas e uma dezena de equações matemáticas, sem ligações concretas com o cotidiano. As experiências anteriores da maioria dos indivíduos, em sua vida escolar, foram no sentido de uma ciência puramente descritiva, acadêmica, muito diferente dos princípios que devem nortear o ensino atual de ciências.

Os parâmetros Curriculares Nacionais (PCNs) propõem um currículo baseado no domínio de 
competências básicas, que tenham vínculo com as diversas situações do cotidiano dos alunos, buscando dar significado ao conhecimento escolar, mediante a contextualização dos conteúdos trabalhados em sala de aula (ROMANO, 2004).

E completa Castro, et al: "[...] Assim, enquanto educadores devemos romper com uma diretriz de conteúdo e estanque, trazendo cada vez mais para a sala de aula temas modernos, mais próximos da realidade dos alunos [...]" (CASTRO, CORREIA e GONÇALVES, 2003, p.3).

O professor não deve esquecer que "a Física é uma ciência de caráter experimental, pois ela esta sujeita não apenas a cálculos, formula e simulações numéricas [...] Esta sujeita também a pesquisa no campo da investigação experimental" (BORGES e ALBINO, 2007). Portando, deve conter recursos que viabilizem a prática experimental em sala de aula.

Assim, diante da realidade proposta pelos PCNs, o professor de Física deve sempre procurar justificar a sua prática pedagógica, a contextualizando com o dia a dia do estudante, ou até mesmo com a própria história de ciência (BRASIL, 2007). É dessa forma que o discente compreende a evolução do conhecimento cientifico ao longo do tempo, observando assim que a Física não é um ramo do conhecimento fechado e acabado, mas sim, em constante transformação (ou evolução).

Diante desta afirmação, é fácil perceber a importância de experimentos em sala de aula. Já que estes trazem o conhecimento de uma forma mais palpável e acessível aos alunos. Dessa forma vê-se a necessidade de trabalhar com experimentos, principalmente àqueles que envolvem a participação direta dos alunos já que a pouca (ou nenhuma) prática experimental contribui com demais dificuldades já encontradas no processo de ensino-aprendizagem dessa ciência.

Contudo, não deve-se esperar que essa mudança na metodologia do ensino de Física simplesmente mude de cenário, abandonado parcialmente os cálculos incompreensíveis aos alunos e assumindo uma postura mais conceitual e experimental voltada para o cotidiano. Os docentes atuantes em sala de aula são frutos de uma formação excessivamente matemática. Por isso, que a mudança didática deve ocorrer inicialmente na formação dos futuros professores.

Diante disso, este trabalho busca dar contornos mais densos ao ensino da prática experimental em um curso de formação de professores, definindo o que é uma aula experimental, além de analisar em detalhes experiências e práticas pedagógicas comuns as disciplinas de física experimental, que em sua maioria se restringem a experimentos clássicos, priorizando a repetição e cálculos excessivos e esvaziando-se de conteúdo significativo para um tão logo professor de Física no ensino médio.

\section{FÍSICA EXPERIMENTAL}

Não é de hoje que dificuldades que afetam a educação básica brasileira vêm sendo estudadas e debatidas por grupos de cientistas sociais e estudiosos. Dificuldades estas, que também afetam diretamente o ensino de física e direcionam as reflexões em torno da educação para as causas e conseqüências destes problemas. Com isto, já se podem notar avanços no campo do Ensino de Física. Pois, os Parâmetros Curriculares Nacionais de 2005 (PCNs) já direcionam o ensino para a formação de cidadãos participantes na sociedade, capazes de atuar conscientemente nas esferas sociais em que fazem parte.

Estes parâmetros indicam como deve atuar e o que objetiva a educação brasileira. Segundo 
estes, o ensino de Física deve proporcionar ao aluno a idoneidade para compreender os princípios de funcionamento da tecnologia utilizada pelo homem, já que os recursos tecnológicos da atualidade devem muito de seu desenvolvimento aos avanços conseguidos na Física. Este ensino também deve permitir aos alunos executar atividades que possibilitem desenvolver habilidades como o método científico de análise e organização sistêmica do conhecimento tornando-o um cidadão dotado de uma visão crítica de seu ambiente.

Estas contribuições fundamentais para formação de um cidadão são possíveis porque a Física é uma ciência experimental, metódica e sistematizada, que parte da análise minuciosa de fenômenos em busca das leis fundamentais que o regem. Mas, dificilmente esta ciência pode ser compreendida, de forma aceitável, se seus conceitos não são observados na prática, já que os alunos, principalmente de escolas públicas, possuem uma grande dificuldade em interpretar esses conceitos, sobretudo, devido à abordagem excessivamente matemática dos conteúdos de física utilizada nas escolas (SILVA, 2011)

Dessa forma, a abordagem conceitual é deixada de lado dificultando a interpretação do aluno e impedindo que o mesmo relacione o conteúdo com o cotidiano, e isso reforça a idéia de que a física não está presente no nosso dia-a-dia, sem falar na ausência de aulas experimentais, principalmente no ensino médio, que reforça todos os aspectos negativos citados anteriormente.

A Física Experimental foi praticamente banida do ensino médio no Brasil. A estrutura acadêmica de nossas escolas é um empecilho à prática experimental continuada. Quando muito, os professores mais corajosos realizam duas ou três aulas experimentais por ano. Entenda-se por aula experimental, aquela em que o próprio aluno monta, mede, analisa e tira suas conclusões. (BERGOLD; RUIZ 2005, p. 01)

Percebemos a necessidade de se estudar física de uma maneira mais simples, conceitual, deixando um pouco de lado toda a abordagem excessivamente matemática e evidenciando a fenomenologia de seus conteúdos. Araújo e Abib (2003, p. 176) afirmam que "[...] o uso de atividades experimentais como estratégia de ensino de Física tem sido apontado por professores e alunos como uma das maneiras mais frutíferas de se minimizar as dificuldades de se aprender $e$ de se ensinar Física de modo significativo e consistente."

Por este motivo, o uso de atividades experimentais para o Ensino de Física é largamente indicado por professores, pesquisadores e alunos como uma das maneiras mais eficientes de se minimizar as dificuldades, de aprender e de ensinar Física de um modo significativo e consistente (ARAÚJO SOBRINHO, 2007).

Desse modo, torna-se evidente a necessidade de disponibilizar ao educador em Física um espaço adequado, para a realização de estudos experimentais com os alunos, material que ofereça o potencial de estudo apropriado à disciplina e segurança tanto para o professor como para o aluno. Além de uma formação que favoreça o ensino experimental.

\section{Física experimental e formação docente}

Em primeiro plano, o problema do ensino não-experimental de Física parece ser culpa do professor. Assim como a maior parte dos problemas apontados na educação, o professor é o primeiro a ser indicado como autor deste "crime", pois este optou em não ensinar de forma a 
utilizar experimentos.

Contudo, em um olhar mais atento, percebe-se inúmeros fatores que contribuem para um ensino de Física longe dos Laboratórios didáticos. Um deles é a própria falta do laboratório.

Barbosa, et al (2010), realizou uma análise da situação dos Laboratórios de ciências em diversas escolas da rede pública no Rio Grande do Norte. Foi possível constatar a quase inexistência de laboratórios e equipamentos adequados ao desenvolvimento de atividades experimentais mínimas.

Contudo, é possível sim encontrar laboratórios em algumas escolas, sobretudo na capital e nas cidades pólos do Estado. Lima (2007) aponta outra dificuldade. A carga horária destinada a disciplina, e o tempo destinado a preparação de aulas. Planejar uma aula de laboratório requer uma prática diferente do planejamento da aula do dia a dia. Primeiro, o professor tem que ir ao laboratório, verificar equipamento, muitas vezes montar previamente os kits didáticos, realizar a prática e verificar se tudo esta funcionando corretamente. Além disso, dificilmente um laboratório comporta 30, 40 ou 50 alunos, sendo necessário dividir a turma ou realizar a atividade em outro horário, como turno inverso. Assim, o professor não possui de tempo reservado em sua carga horária para o desenvolvimento dessas atividades, e também não há nenhum incentivo a mais, seja financeiro ou acadêmico.

Por fim, ainda permanece um fator: muitos professores não se sentem aptos a lecionar a disciplina de Física dentro de uma perspectiva experimental. Primeiro, é comum em escolas públicas encontrar docentes que nem mesmo são lecionados em Física. Há desde engenheiros e matemáticos passando por pedagogos e historiadores lecionando física. E mesmo os devidamente formados em Física, não se sentem confortáveis quando o assunto é aula no laboratório.

Essa problemática motiva a realização de inúmeras produções científicas, com sugestões de atividades e práticas experimentais simples, produzidas com matérias de baixo custo e acessíveis em qualquer lugar do país. Inclusive os atuais livros didáticos de física vêm recheados de experimentos e pequenas práticas.

Assim, o ensino de Física Experimental fica condicional a presença de três fatores fundamentais: A Escola (Laboratório); O Professor (Formação Docente) e material de apoio (livros didáticos e equipamentos).

\section{METODOLOGIA}

A nova abordagem de ensino sugerida pelos Parâmetros Curriculares Nacionais para o Ensino Médio - PCNs propõe uma "educação para a vida". Contudo, as práticas de laboratório não podem permanecer restritas aos laboratórios das instituições formadora dos futuros professores. Por isso faz-se necessário uma verificação do ensino experimental de física nas principais escolas de ensino médio do Rio Grande do Norte, para que dessa forma possa se construir uma idéia de como se encontra essa prática atualmente.

A eficiência no uso dos laboratórios também está diretamente ligada a formação acadêmica dos responsáveis por seu uso, ou seja, a formação dos professores de Física. Este é outro aspecto a ser verificado pela pesquisa. Diante disso, este trabalho definiu suas ações em dois momentos distintos: 
Primeiro: Verificar a existência da prática experimental nas escolas de ensino médio (públicas e privadas). Para esse quesito, analisar as melhores escolas do Rio Grande do Norte, segundo o conceito IDEB - Índice de desenvolvimento da educação básica. Foram observados fatores como a existência de espaço físico, a quantidade disponível de equipamento de laboratório e a possibilidade de aquisição ou construção de experimentos de baixo custo, bem como um questionário rápido para os docentes, levantando informações quanto a sua formação e sua prática pedagógica na disciplina de Física.

Dessa forma, pré-supõe que uma escola com bom IDEB, é uma escola de "qualidade", e uma escola com baixo IDEB, é uma escola que merece atenção especial por parte do governo, sobre tudo se a "distribuição" de IDEBs baixos se concentrarem em determinada região da cidade, estado ou federação.

Sendo os dados públicos, através do portal do INEP (http://www.inep.gov.br/), é possível para a sociedade acompanhar os resultados das escolas, dando poder a população de fiscalização e exigência da qualidade da educação nas escolas de sua região.

Vale destacar, que na seleção das escolas públicas, optou-se por excluir da lista as escolas da rede federal, tendo em vista que sua realidade é muito distante das escolas públicas das redes Estaduais e Municipais.

Por fim, um questionário foi elaborado e levado aos alunos das Licenciaturas em Física. Nesse segundo momento, a aplicação do questionário, com os alunos da licenciatura em Física (ingressantes, concluintes e alunos de Física Experimental), nos trouxe informações claras sobre o que esta ocorrendo nos curso de Física. No Instituto Federal de educação ciência e Tecnologia do Rio Grande do Norte - IFRN, existe oferta de licenciatura em Física na modalidade presencial em três cidades, além da capital. Vale colocar que outras instituições de ensino superior também ofertam vagas para a Licenciatura em Física (presencial e a distância), embora esta pesquisa se detenha as ofertas dos campi do IFRN.

Diante dessas respostas, serão elaboradas estratégias de incentivo a prática experimental, a partir do desenvolvimento de oficinas e mini-cursos, voltados aos alunos da rede pública, como também atividades específicas para os docentes e futuros docentes. Pretende-se com essas ações propor a melhoria do ensino público, e perceber uma contribuição substancial a formação dos professores de Física.

\section{Questionários}

Para a construção desse trabalho, foram elaborados dois questionários. O primeiro para os docentes presentes nas escolas selecionadas pelo critério IDEB, destacado acima, e o segundo utilizado com os alunos do curso de Licenciatura em Física

O questionário é um dos principais instrumentos de levantamento de dados de campo deste trabalho. Por isso, a sua elaboração foi feita de forma que este pudesse ser capaz de coletar o máximo de informações possíveis, de forma rápida, simples e relevantes para a construção das estatísticas dos profissionais docentes que estão atuando no ensino (ou não) de Física experimental.

O questionário possui ao todo treze questões, sendo que as três primeiras questões fazem referência ao levantamento da formação acadêmica dos profissionais, como o grau de formação (apenas ensino médio, magistério, graduado, especialista, mestre ou doutor) e a área de formação. Outro ponto importante é se a escola pública possui laboratório de Física (ou ciências). 
Na questão seguinte, é feito um levantamento sobre quais conteúdos de Física experimental são abordados em sala de aula. Caso o professor não ministre nenhum conteúdo com esta metodologia, ele deveria deixar de responder o campo do questionário referente a didática e metodologia sobre o ensino de Física experimental (questões cinco a doze), partindo assim, para a última questão.

As respostas dessas questões são de extrema importância, pois elas são o suporte para o levantamento estatístico de dados, e conseqüentemente para as conclusões e possíveis soluções da situação em que se encontra o ensino no Estado do Rio Grande do Norte, quando se fala em experimentos de Física.

Todos esses resultados foram agrupados e analisados, e detalhados neste trabalho. A última questão faz referência a proposta de um mini-curso sobre práticas de laboratório, devido a possibilidade do questionário revelar uma possível deficiência na formação dos docentes, pois esperava-se que alguns destes tiveram uma formação experimental adequada.

Na segunda etapa, um questionário foi elaborado e levado aos alunos das Licenciaturas em Física dos quatro campi do Instituto Federal de Educação Ciência e Tecnologia do Rio Grande do Norte. O primeiro campus é na capital do Rio Grande do Norte: Natal. Os demais campi estão localizados nas cidades de João Câmara (80 km), Santa Cruz (120 km) e Caicó (280km).

O processo de expansão da rede federal de educação tecnológica, por meio da Lei 11.892, de 29/12/2008, transforma os Centros Federais de Educação Tecnológica em Institutos Federais de Educação, ciência e tecnologia, que possuem a obrigatoriedade de oferta de $20 \%$ de suas vagas para cursos de formação e qualificação de professores.

Assim, a expansão cria unidades no interior do Estado, levando cursos de licenciatura aos vários pontos do Estado, estando a Licenciatura em Física nas cidades já mencionadas. Em poucos anos, esses formandos estarão atuando nas escolas da rede básica de ensino em todo o estado, não sendo mais necessário o deslocamento para à capital, para a obtenção do curso de Licenciatura, já que nem sempre o retorno ao interior ocorria.

No entanto, é necessária formação de qualidade, e quando falamos em Física, essa qualidade passa, também, por laboratórios e práticas experimentais. Nessa etapa final, foi elaborado um questionário, que foi levado aos discentes do curso de Física nos quatro campi. O mesmo questionário foi aplicado a ingressantes e concluintes. Acrescenta-se a este os alunos pagando as disciplinas de Física experimentais. Os resultados foram confrontados e detalhados no tópico seguinte.

\section{RESULTADOS E DISCUSSÕES}

Conforme a metodologia adotada, os instrumentos de levantamento de dados foram levados aos professores das escolas selecionadas conforme o seu indicador IDEB, totalizando dessa forma 20 escolas, 10 públicas estaduais e 10 privadas. Outro questionário, voltado aos alunos do curso superior de Licenciatura em Física, foi levado para ser respondidos pelos alunos, em quatro cidades, a capital do Rio Grande do Norte, e outras três cidades-pólos, no interior do Estado. 


\section{Ensino de Física Experimental no Ensino Médio}

Os questionários foram respondidos por um professor em cada escola. Inicialmente, o questionário realiza o levantamento da formação do professor, já que é muito comum professores com outra formação estarem lecionando a disciplina de Física, sobre tudo nas escolas da rede pública.

A primeira questão identifica o nível de formação dos professores. Todos os docentes encontrados nas escolas privadas possuem, no mínimo, graduação, sendo que $30 \%$ destes possuem cursos de pós-graduação. Já nas escolas públicas, foi possível encontrar professores apenas com Magistério (10\%) e alguns ainda na situação de alunos de graduação (30\%). Os pósgraduados representam um quantitativo de $20 \%$, sendo que os demais possuem apenas graduação.

Em relação a área de formação, é importante frisar, que nem sempre o professor que esta lecionando Física, possui formação em Física. Dentre os docentes das escolas públicas, foi possível encontrar licenciados em matemática, em pedagogia/magistério e em química ministrando aulas de física. No caso mais divergente, havia professor com formação em zootecnia a frente da disciplina. Esta situação não foi observada nas escolas particulares, já que todos os professores que lecionam física, são licenciados em Física.

O número de Estagiários nas escolas públicas chegou a 30\%. Para completar uma carga horária mínima para o contrato de estágio, é comum o aluno-estagiário assumir disciplinas diferentes de seu curso de formação. É o caso de diversos alunos de Licenciatura em Física estarem também ministrando aulas de matemática, e alunos de Licenciatura em Química estarem simultaneamente em turmas de Física e Química. Na rede privada, professor de Física se mantém lecionando apenas Física.

A seguir, o questionário realiza o levantamento da experiência e metodologia do professor. Na rede privada, têm-se professores com maior experiência, sendo que muitos possuem entre 5 e 10 anos a frente da disciplina de Física (40\%), entre 3 e 5 anos (30\%) e entre 1 e 3 anos (30\%) completam o restante dos entrevistados. Não foram encontrados professores com menos de 1 ano. Contudo, na escola pública, a situação é inversa, já que 40\% alegaram possuir menos de 1 ano, e 30\% entre 1 e 3 anos. 20\% possuem experiência entre 3 e 5 anos e o restante possuem experiência de entre 5 e 10 anos.

Isso se deve ao fato de muitos professores iniciarem sua carreira nas escolas públicas, sejam como estagiários, contratados ou concursados. Contudo, os baixos salários e as péssimas condições de trabalham, impulsionam estes docentes a ocupar as várias vagas na rede privada, já que disciplinas como Física e Química carecem de quantitativo de profissionais no cenário atual. Esse "êxodo" não ocorre com a mesma intensidade nas cidades do interior, já que a escola pública é geralmente a única oferta de ensino, sendo baixo o número de escolas privadas de ensino médio.

Uma outra diferença entre os docentes das escolas esta na modalidade de ensino. Todos da rede privado lecionam apenas para o ensino médio regular (e cursinhos pré-vestibulares). Já os docentes da rede pública, além do ensino médio regular, lecionam também em turmas de Educação de Jovens e Adultos - EJA.

Quando questionados qual série lecionam geralmente, pode-se perceber que os docentes das escolas particulares possuem uma maior constância em determinada série. É comum um 
professor de 10 ano, assumir diversas turmas de 1 을 ano durante dois ou três anos seguidos. Embora não exista uma regra, raramente os professores estão lecionando nas três series no mesmo ano letivo. Na rede pública, o mesmo acontece nas escolas com um maior número de alunos, possuindo dois ou três professores de Física por turno. Nas escolas menores, um único professor assume todas as séries.

Sobre os recursos didáticos, todos afirmaram utilizar quadro e giz. É importante destacar que nem todos afirmaram fazer uso de Experimentos de Física em suas aulas. Em algumas escolas particulares, os professores alegaram que existe um professor especifico de laboratório.

A questão seguinte faz referencia à quais conteúdos de física são abordados de forma experimental. Todos os professores afirmaram fazer uso de experimento em mecânica e hidrostática. Praticamente todo o kit de física experimental possui experimentos para serem utilizados nas aulas de mecânica e hidrostática. Talvez por ser um dos itens mais baratos, por se tratar basicamente de blocos e vidraria.

Aos professores, foi questionado se na instituição de ensino existem os materiais adequados para o ensino de Física Experimental em sala de aula. A grande maioria das escolas privadas (70\%) respondeu que sim. Em contra partida, todos os professores da rede pública afirmaram que as escolas não possuem condições suficientes para o ensino experimental. Estes mesmo professores afirmaram que não se sentem habilitados para trabalhar com práticas experimentais, e caso houve-se a oportunidade, participariam de um curso de qualificação em Física Experimental. Em relação aos professores da rede privada, $60 \%$ responderam que se sentem habilitados, e todos afirmaram que participariam do curso de capacitação.

\section{Ensino Física Experimental na formação docente}

O questionário destinado aos alunos dos cursos de Licenciatura em Física do IFRN foi respondido pelos alunos, conforme a metodologia adotada. Os resultados encontram-se expressos a seguir. No total, foram respondidos e analisados 147 questionários. Quando necessário, há distinção entre as respostas fornecidas pelos alunos ingressantes ( 1 e e 2 período de curso), alunos Cursando Física Experimental ( 3 ao 6ำ período do curso) e alunos concluintes (7으 e 8 o período do curso).

Na primeira questão os alunos apenas identificam a sua situação no curso: i) Ingressante, ii) cursando alguma disciplina de Física Experimental ou iii) Concluinte. Como é de se esperar, a maior parte dos alunos que responderam o questionário estão cursando alguma disciplina de Física Experimental. Isso se deve ao fato dessas disciplinas se estenderem do 30 ao 60 período, correspondendo a 4 semestres de um curso de 8 semestres letivos.

O percentual dos ingressantes ( 1 e e 2 o período) desse é maior que os dos alunos concluintes (último ano de curso), o que é normal, já que as turmas concluintes possuem bem menos alunos que as turmas iniciantes, em virtude de desistência, trancamentos e reprovações.

A questão 02 traz quatro situações distintas. Na primeira, a) "O professor traz um experimento, na sala de aula convencional, coloca sobre a sua mesa e realiza algumas demonstrações para os alunos." Na segunda situação, b) "O professor entrega uma planilha, com os dados obtidos de medições reais aos alunos, e pede que estes façam os cálculos da média, desvio padrão, incertezas, além de ter de traçar alguns gráficos." Na próxima situação c) “O professor passa uma tarefa para casa, em que esta tarefa consiste na construção de um 
experimento, conforme tema detalhado teoricamente em sala de aula." E na última situação d) "O professor realiza uma prática, onde os alunos de dividem em grupos, montando experimentos a partir de kits experimentais, e realizando medições.".

Assim, os alunos são questionados sobre qual dessas situações ele considera uma aula experimental, no ensino médio.

$\mathrm{Na}$ análise geral, as quatro situações ficaram praticamente empatadas, embora o maior número de respostas tenha sido em torno da quarta situação, que predominou entre os cursantes e concluintes, mesmo sendo minoria entre os ingressantes.

A situação quatro é a situação típica de uma aula de Física Experimental no curso superior: divididos em grupos, os alunos montam experimentos pré-determinados através de kits didáticos e/ou equipamentos disponíveis. Assim, é comum o aluno imaginar que uma aula experimental no ensino médio deva seguir os mesmos moldes da aula nas disciplinas experimentais.

Apenas $16 \%$ dos ingressantes selecionaram essa situação. Isso se deve, provavelmente, ao pouco contato com esse tipo de metodologia no ensino médio. Em contra-partida, $46 \%$ dos ingressantes optaram pela primeira situação, onde o professor traz um experimento, na sala de aula, coloca sobre a sua mesa e realiza algumas demonstrações para os alunos. Essa é a forma mais comum do experimento surgir no contexto da sala de aula para o ensino médio.

Sem disciplina, ou carga horária específica para laboratório, os professores acabam tendo que inserir o experimento de forma rápida e dinâmica, sem espaço para debates e análises críticas, e menos ainda para interagir com o aluno.

É importante destacar que a situação b) faz referência ao tratamento e análise estatística dos dados, e a situação c) se relaciona com a construção experimental por parte dos alunos. Os valores semelhantes entre os três grupos sugerem que essas práticas estão presentes tanto no ensino médio como no ensino superior, de forma bastante semelhante.

A questão 3 aponta a relação do ensino experimental com o material didático. Neste caso, se questiona quais tipos de livros que poderiam ser empregados como material de apoio ao docente que pretende desenvolver uma aula experimental. Nas opções possíveis, têm-se livros de ensino médio; livros de ensino superior; livros de tratamento de dados; livros de simulações computacionais e livros de física experimental.

Dentre as opções, o destaque vai para "livros de ensino médio", que possuíram a maior valor percentual. Os livros de ensino médio tendem a ser mais gerais, aprofundam menos e muitos deles buscam sugerir atividades experimentais de fácil realização, como foi possível analisar neste trabalho. Dentre os ingressas, predominou o livro de ensino médio, devido, provavelmente, ao maior conhecimento deste em relação aos demais.

Livros de Física do ensino superior clássicos em cursos de Física, como o Hallyday, Sears e Moyses, estão entre as próximas opções dos alunos questionados. Esses livros trazem muito ou nada de proposta experimentais, já que dedicam as construções teóricas do conhecimento físico básico e resolução dos exercícios. Essa opção pode ter sido influenciada pelo uso constantes desses livros ao longo do curso.

Tratamento de dados e simulações computacionais figuram entre as últimas opções. Embora sejam passos fundamentais para a realização de pesquisas em Física Experimental (simulações antes das montagens e tratamento de dados após resultados), não parecem ter grande 
aplicabilidade como suporte para aulas de ensino médio.

Os livros de Física experimental tiveram os maiores valores percentuais. Tais livros abordam os conteúdos das propostas anteriores, embora existam poucos livros que sejam, de fato, de Física experimental.

A última questão é questão 04 , que coloca que em dada situação, o discente é solicitado a realizar uma aula experimental. Contudo, este não possui acesso a Laboratório ou equipamentos, devendo, portanto, pensar em uma alternativa. Dentre as opções, têm-se: i) a utilização de um software de simulação, com toda a turma, ii) trazer um vídeo de dado experimento, e explicaria em sala de aula e iii) passar uma atividade experimental para casa, para construção dos alunos.

Como é de se esperar, a terceira alternativa obteve o maior percentual de escolha, alcançando $44 \%$ na média das respostas, seguido pela utilização do vídeo com $30 \%$ e o uso do software figura em último, com $26 \%$.

Entre os ingressantes e os cursantes parecer haver um perfil bem próximo de resposta. A opção "utilização de software" obtêm 33\% com os ingressantes, cai para 28 \% com os alunos no meio do curso e acaba $12 \%$ entre as opções dos concluintes. Isso aponta para uma mudança de mentalidade em relação ao uso de software, em substituição as práticas de laboratório. $\mathrm{O}$ uso da "atividade experimental para casa" ganha cresce bastante entre as opções dos concluintes. É importante destacar que a sala de aula e o laboratório não são os únicos espaços de aprendizagem para se aprender Física.

\section{CONCLUSÕES}

Após a realização, análise e aplicação dos questionários, pode-se concluir que a pesquisa cumpriu com o seu objetivo, já que esta pôde detalhar de forma mais clara a situação da formação docente e o ensino de Física Experimental no Rio Grande do Norte, tendo em vista que as escolas com melhores indicadores IDEB foram visitadas, e quatro cursos diferentes de física foram analisados, verificando as respostas de seus alunos, que serão os futuros professores.

Em relação ás escolas, é fácil perceber que o ensino de física insiste em permanecer no tradicionalismo, com aulas puramente teóricas-matemáticas. Mesmo as aulas experimentais não estando totalmente presente nas escolas, conclui-se que existem condições para o desenvolvimento das práticas de Física experimental, e que pouco a pouco essa questão vem se consolidando. Esse fato pode sofrer influência direta dos Livros didáticos, pois esses são elementos que entram na sala de aula, estando o tempo todo disponível para os alunos.

Analisando os futuros professores de Física do Rio Grande do Norte, em quatro cidades distintas, espalhadas por todo o estado, pode-se constatar que existe uma mudança de mentalidade em relação ao ensino experimental, e que a nova safra de professores esta disposta a trazer essa abordagem as escolas da região.

Sabe-se que este trabalho pode desencadear pesquisas futuras, complementando elementos que aqui não foram abordados, como uma análise mais profunda dos professores em atividade, e elaboração de cursos de capacitação e como trabalhar aulas experimentais modelos, sendo essas propostas para trabalhos futuros. 


\section{AGRADECIMENTOS}

Aos professores de Física do IFRN, e das escolas visitadas, que contribuíram com a aplicação do questionário. Agrademos também aos alunos envolvidos no processo, sobre tudo os futuros professores presentes nos nossos cursos de Licenciatura.

\section{REFERÊNCIAS BIBLIOGRÁFICAS}

1. ALVES, Rubem. Filosofia da ciência: Introdução ao jogo e a suas regras. Edições Loyola, 12ạed. São Paulo, 2000.

2. ARAUJO SOBRINHO, Antônio; SOUZA, Gilberto M. P. Óptica física e geométrica. Natal: Editora CEFET, 2007.

3. ARAÚJO, M. S. T.; ABIB, M. L. V. S. Atividades Experimentais no Ensino de Física: Diferentes Enfoques, Diferentes Finalidades. Revista Brasileira de Ensino de Física, v. 25, n. 2, 2003, p.176-194.

4. BARBOSA, A.S, et al. ANALISE E ADEQUAÇÃO DA PRÁTICA DOCENTE DE FÍSICA EXPERIMENTAL NA REGIÃO DO MATO GRANDE. Revista Holos (Online), v.5, p.235 - 243, 2010.

5. BERGOLD, Arthur W. B; RUIZ, Victor H. V. Anistia da física experimental no ensino médio: iniciando um laboratório didático de física. In: XVI Simpósio Nacional de Ensino de Física, 2005. Rio de Janeiro.

6. BORGES, J. C. S., ALBINO JUNIOR, A., A MOSTRA ANUAL DE FÍSICA DO RN: Ciência acessível a todos. Revista Holos (Online), v.3, p.16 - 25, 2007.

7. BRASIL, Ministério da Educação. Parâmetros Curriculares Nacionais: Ensino Médio. Brasília: MEC; SEMTEC, 2002.

8. CASTRO, Ronaldo A. de; CORREIA Filho, João A.; GONÇALVES, Heitor A., A inserção da física moderna no ensino médio, in: XV Simpósio Nacional do Ensino de Física, p 1780 - 1789, 2003.

9. FERNANDES, Reynaldo. Índice de Desenvolvimento da Educação Básica (Ideb) / Reynaldo Fernandes. - Brasília: Instituto Nacional de Estudos e Pesquisas Educacionais Anísio Teixeira, 2007.

10. LIMA, A.L.; et al. Qualificações profissionais dos professores de Física do ensino médio da Mata Norte de Pernambuco, ata do XV Simpósio Nacional do Ensino de Física, p 1898 - 1904, 2003.

11. LIMA, Makson Rocha.O ensino de física nas escolas estaduais do RN: um apredizado limitado pela carga horária. Monografia: Licenciatura em Física. CEFET-RN. Natal-RN, 2007.

12. PNLD 2012: Guia de Livros didáticos: Física. Brasília: Ministério da Educação, Secretaria de Educação Básica, 2011.

13. NEVES, Marcos Cesar Danhoni; SAVI, Arlindo Antônio, A Sobrevivência do Alternativo: Uma Pequena Digressão Sobre Mudanças Conceituais Que Não Ocorrem no Ensino de Física. Revista Ciência \& Educação - Vol. 6, Nº 1, 2000

14. ROMANO, Jair Carlos. Governo do Estado do Rio Grande do Norte: Ensino Médio de qualidade. Física. Natal: Sistema de Ensino Holos, 2004. 
15. ROSA, C.W. e Rosa, A.B.; Ensino de Física: objetivos e imposições no ensino médio. Revista Electrónica de Enseñanza de las Ciências. v. 4 n 1, 2005

16. Silva, Ed-Ek Soares. MEDINDO A GRAVIDADE: Análise estatística de Experimentos como prática de ensino. Monografia: Licenciatura em Física. IFRN. Natal-RN, 2011.

17. SOUZA, T. C. F.. Avaliação do ensino de física: um compromisso com a aprendizagem. Ediupf, Passo Fundo, 2002. 